\title{
The Temptation of Getting the "Pie"----- The Cost-benefit Analysis on Farmer Specialized Cooperatives Access to Government Subsidies in Mainland China
}

\author{
Ying Zhang \\ Phd student, College of Humanities and Development Studies, China Agricultural University \\ No.17 Qinghua Dong Lu, Haidian District, Beijing 100083, China \\ $\&$ \\ Visiting Scholar in the OARDC (Agroecosystems Management Program), Ohio State University, USA \\ Tel: 1-330-234-6572 (America) E-mail: michillezhang@yahoo.com.cn \\ Dapeng Ren \\ Phd candidate advisor, College of Humanities and Development Studies, China Agricultural University \\ No.17 Qinghua Dong Lu, Haidian District, Beijing 100083, China \\ E-mail: law@cau.edu.cn
}

Received: March 22, $2011 \quad$ Accepted: April 2, $2011 \quad$ doi:10.5539/ijbm.v6n9p24

\begin{abstract}
In the Chinese mainland, government subsidies look like a delicious "pie" hunted by different cooperatives. In order to get more charge of it, however, some cooperatives used strategies distorting the cooperative's basic characters. These problems appeared also decline the capital usage efficiency of government subsidies in a certain extent. This paper uses transaction cost theory to explore the current situation and the cost/benefit existed in different cases. The authors believe that the win-win options for Chinese cooperatives are getting the supportive resource, developing themselves and profiting from the market as well. In the end, authors suggest that the financial subsidies should be more used on building a public service platform to realize more and more cooperatives benefiting.
\end{abstract}

Keywords: China, Farmers' Specialized Cooperatives (FSCs), Government subsidy, Cost-benefit

\section{Introduction}

According to the data from the State Administration for Industry \& Commerce of China, the number of registered Farmers' Specialized Cooperatives (FSCs) has already over 350,000 at end of the year 2010. The rapid growth in number is partly due to the implementation of Law of the PRC on Specialized Farmers Cooperatives (2006) which removed many former institutional barriers. Furthermore, this growth is closely linked with subsidies to FSCs (Note 1) provided by center and local governments. Chapter 7 of the cooperatives law specifically states that government should provide support for formation and development of FSCs. However, it is the abundant government subsidies that stimulate the growth in the number of FSCs with an over dramatic speed.

In rural China, the motivations of establishing FSCs are very complicated. Some FSCs do not aim to satisfy all members' common interests, instead, focusing on acquiring government subsidies. Meanwhile, the 'number talks' fact pushes local government into encouraging more and more famers to form FSCs in order to achieve better performance. The abundant Chinese government subsidies look like a delicious "pie" to those FSCs who constantly adjust their strategies in order to acquire them. However, some of their strategies to secure the subsidies have deviated from classical cooperatives' principles. Apparently, these issues are caused by many reasons. The authors consider the main reason is that FSCs' limited cost-benefit awareness on gaining and using government subsidies do not match the original intention of government policy. Therefore, cooperatives can make more efficient use of subsidies by identifying the apparent or hidden costs, risks and benefits while trying to gain the "pie". Related government policies should also aim to make clear all costs, risks and benefits involved as well. 


\section{Reasons and current situations on government subsidies}

Why should Chinese government provide abundant financial support to FSCs? On the one hand, it mainly depends on the weakness of farmers and agriculture. Because the interests of FSCs are consistent with the interests of farmers, the government is willing to promote agricultural sustainable development and encourage improved agricultural efficiency by supporting FSCs. On the other hand, one of the distinctive features of the cooperative business form is the promotion and adherence to a set of principles. Commonly accepted principles including voluntary organizations, democratic control and concern for community are consistent with the idea of good governance. Consequently, the growth of FSCs is good for both improving farmers' livelihood and the construction of harmonious society.

As for this question, obviously there are no divergent views among different scholars. Xiaoshan ZHANG and Peng YUAN (1991) hold the view that the government should only provide financial support and other incentives to FSCs through legislation, cooperatives education, extending agricultural technology and marketing management knowledge and so forth. They also believed that intervention in the formation and growth of FSCs is not so-called "the first driving force" in providing government financial support. There is no doubt that cooperatives are autonomous, self-help organizations controlled by their members (Note 2), while too much intervention would be detrimental FSCs must still be anchored to deal with government and other institutions. From the dynamic point of view, Peng YUAN (2001) considered there were non-equilibrium mutual penetrations and interactions between the state and cooperatives. To be specific, the government has strong penetrating impact on FSCs, meanwhile, the cooperative business themselves become independent and gradually differentiate. Based on the field investigation materials in Jiangsu and Zhejiang Provinces, Jingxin WANG (2005) found government support is necessary for FSCs' growth. Government should used measures to ensure FSCs can run their business in a more favorable environment, that they are enacted by a local decree, given tax preference and improved credit services to establish agricultural insurance and risk fund,etc. Xiangzhi KONG and Yanqin GUO (2006) used non-random sampling method to investigate FSCs in 23 provinces of the Chinese mainland. They also found out that government support was helpful and necessary in the development of FSCs, especially during their formation time. However, the reality also showed government support in the policy and financing areas are still insufficient in general.

In the case of Beijing Municipal, the growth trend of FSCs' number experienced three distinctive stages during 2007-2010. To be sure, the number experienced a rapid growth and then followed by a relatively flat period. After that another sharp increase appeared. According to the statistic data (Note 3), with the implement of the Law of the PRC on Farmers Specialized Cooperatives, the FSCs' number reached 1609 in the year 2007. During the following one year time, only 707 new cooperatives registered. On the contrary, the increasing number rose to 2079 from 2008 to 2010. Compared with the year 2009 and 2010, the rate of growth in 2008 was far less than the other two years.

\section{$<$ Insert Figure 1 here $>$}

As for the first phase of FSCs' development in Beijing, due to the implement of the law which effectively cleared away the existing institutional barriers, there was a rapid growth of the number immediately appeared. This situation was the result of long-term systematic block. Therefore, after resolution of the related problems, especially where/how to register, a large number of FSCs will format for sure. Things were changed in the second phase, the impact of registration system was gradually digested, and systematic congestion problems did not exist. In this phase, the main purpose for establishing FSCs is farmers consider their own situation and use collective action in order to pursuit the normality market returns. The increasing trend gradually slowed down and the constant growth emerged thereafter. Under the ideal state, this situation would continue. However, the FSCs in Beijing showed the third increasing phase. This phenomenon proves the new institutional temptation concentrating in government subsidies play an essential role in FSCs' original development space.

To maximize the benefits, FSCs prefer pay nothing or small amount of costs to gain substantial increasing profits and to reduce the operating costs as well. When government subsidies as a delicious "pie" placed in front of cooperatives, it becomes an additional received income except the general input-output relations to FSCs. This becomes the main driving force for FSCs to get the "pie". However, the government subsidies do not belong to the generalized system of preference, there must be several corresponding conditions included. The cost FSCs should pay for preparing and meeting all these conditions are the potential cost existed in getting the "pie".

Also, the target FSCs will be selected by government step by step from all FSCs which will meet their requirements. It is not 100 percent for sure that all FSCs which meet the government requirement will get the subsidies. Therefore, FSCs need to assume the additional risk just in case they cannot get the governmental incentives. Similarly, to those FSCs which already got the government subsidies, the existing risks are mainly focus on their direct/indirect impact on their capital structure changes, patronage refund and organizational governance structure. Furthermore, when government provides subsidies to the FSCs, it should consider more on the usage efficiency of financial resources, as well as the impact on the normalization of FSCs. As for the cooperatives, it is necessary to make corresponding benefit-cost analysis before making further strategies to 
reduce the costs of pursuing government subsidies and their negative effects on the FSCs ' sustainable development.

\section{The cost-benefit analysis on obtaining government subsidies}

In the broadest sense, transaction cost include all those not exist in the absence of property rights, no trade, not one kind of economic organization of Robinson Crusoe the cost of the economy. This definition of transaction costs can be seen as a series of system cost, including information costs, negotiation costs, costs of development and implementation of contracts, property rights define and control the cost of supervision and management of costs and the cost of structural changes in the system. In short, including all material not directly in the cost of the production process. (Wuchang ZHANG, 2000) Also, organization can be seen as a constantly changing entity. The organizational structure continues changing due to the complexity and uncertainty of surroundings. In particular, when organizations interact with the external environment, they need to pay the cost on every transaction part without any exempt. Apparently, the costs of some transactions are higher than the others. As for the government subsidies, there are all kinds of transaction costs existing in different competing, obtaining and using process. Government would like to set up a number of regulations to narrow down the quantity of supported objects. Therefore, FSCs should adjust their organizational structure in order to satisfy these requirements. Taking the Yanqing District of Beijing as an example, the local government introduced the new government document "About the implementation details involved in supporting FSCs in Yanqing District" (Note 4) (2007). The Article IV regulated "Government should provide appropriate subsidies to FSCs while they establish their own website". Obviously, every step of having a website needs financial and technical inputs, including establishing, post-maintenance and management respectively. In fact, cooperatives can use the current marketing platform to self-promote and sale their products. And the involving cost may far less than building an entirely new website. Meanwhile, because of the limited extension system, other stakeholders have a little awareness on the new website. Therefore, it cannot effectively improve the current sales conditions. As for the risks created in hunting for government subsidies, they are assumed by cooperatives which may negatively influence the sustainability of cooperative's development and the improvement of members' income in a certain extent.

When authors analyze the cost-benefit existed in obtaining government subsidies, it is important to classify these target FSCs into two groups, that they are FSCs which have already met government conditions and others have not. In order to meet these requirements, the latter group would make strategies including changing the current organizational structure, product structure and so forth. When FSCs try to get scarce resources from government, some of their strategies may cause the changes of their cooperative's character. In addition, these changes may also influence the governance structure of the organization and some of these changes may be internalized into their cooperative's characteristics forever. On the contrary, other strategies are potentially implicated with special phases, cooperatives may abandon these after experiencing a certain stages.

The whole process of struggling and digesting governmental subsidies all involve transaction cost FSCs may pay. The net profit of FSCs obtaining government subsidies may be calculated by the formula 'the obtained government subsidies - transaction cost $=$ net profit'. If FSCs pay much transaction fee and the income is less than the cost, so the net profit will be negative. However, the reality in the field is much more complex which made the evaluation of transaction cost and net profit could not simply equivalent to one plus one must equal two. Usually, the quantity and quality of government subsidies received by a specific FSC should much more than the cost paid by the entity itself. However, to a specific FSC, factors involving the uncertainty and heterogeneity of transaction and asset specificity may lead to the uncertainty that cooperative whether can get government subsidies for sure after paying the related transaction cost. This phenomenon typically refers to the term aleatory (Note 5) in fields of law. In general, the whole quantity of government incentives is limited and scarce as well, oppositely FSCs' desires for getting them are far beyond. On the one hand, the dramatically number growth of FSCs in the Chinese mainland has already caused heated competitions among the same type of FSCs even in the same region. On the other hand, it is not the equivalent payment between cooperative and government when cooperatives try to. FSCs are willing to accept the competition among FSCs and take the full responsibility of getting nothing. From this aspect, FSCs' strategies contain speculative motive in some extent. In other words, this so called "press one's luck" behavior makes if cooperative will not get the chance to obtain the government subsidies, so that the organization could only digest the former paid transaction cost without any income.

As for obtaining government subsidies, it does not mean the organization can successfully get it without any doubt when FSCs meet government's requirements. Cooperatives merely get the chance to fight for these resources. And then, here comes three possibilities: Firstly, there are only costs existed but any income for return. To be specific, although FSCs make gestures to struggle for and adjust its organizational structure, it still merely get the chance but the real resource. Hence, there is no income for FSCs to cover the paid transaction cost fee in this occasion. Secondly, some FSCs pay for the cost and also gain the income (got the government subsidies). There is net profit still existed after the deduction. However, this case only existed in the intuitive economic interest aspect, that is after cooperative paying the cost of getting the subsidies, it successfully obtain the resource. Moreover, the quantity of gained resource is larger than the transaction cost fee, therefore the space of 
cooperative's net profit exist. Thirdly, the transaction cost FSCs pay coincidently lead the enhancement of their marketing power. Besides the government subsidies they get, there is another profit of getting incentive exist. Unlike the other two classifications above, it is this kind of FSCs' strategies improve their adaptation ability to the market during the fighting process, thus the measurement of the net profit they gain should deduct transaction costs from the return.

The previous analysis is based on using cooperatives as the major unit of analysis. Because cooperative is a collective union, their strategy making embodies their members' common needs and willingness. According to the Law of the PRC on Farmers Specialized Cooperatives (2006), there are no particular regulations on members' capital requirements, correspondingly the related members' responsibilities are all specified statement in cooperatives' bylaw. According to the Article 18 of the Law, a member of a FSC shall be charged with the duty to make capital contributions to the cooperative as stipulated in the charter. In other words, the bylaw of FSCs can make specific requirements on the amount, methods and procedures of capital contribution. Meanwhile, it can also make no requirements for any capital contribution, that is members don't need to have the investor's identity when they decide to join. Therefore, there are four different forms of members' capital contribution methods under the current framework of the law: (1)all members joint and make equal contribution; (2)all members joint but unequal contribution; (3)part of the members make capital contribution and part don't; (4)all member don't make capital investment. (Gang SONG, 2007)Actually, there are membership differences exist in some FSCs in China. In particular, all members in this kind of FSCs can be grouped as core-members and ordinary members. The core-members refer to members who made large capital investment to the cooperative. It is because the unequal capital contribution leads to the differentiation, which will also influence the governance, management control and the distribution of residual claim in cooperatives, existed in the membership structure. For members in this FSCs above, the maintenance of governmental subsidies may lead changes happened in the orders of internal members' relationship. The following requirement in the Law of the PRC on Farmers Specialized Cooperatives shows if the FSCs accept the government subsidies, the money they get need to be documented in every member's account and deemed as members' capital contribution.

... The distributable profits shall be returned or distributed to the members according to the following provisions, and the specific measures for distribution shall be decided according to the stipulations in the charter or the resolution of the membership assembly: ... to distribute pro rata to the members of the cooperative the rest of the profits left after the return according to the provisions in the preceding subparagraph, on the basis of the capital contributions and shares of common reserve funds recorded in the members' accounts and the members' average quantified shares of the assets accumulated from subsidies directly given by the government and donations made by other persons to the cooperative.

(Article 37, Law of the PRC on Farmers Specialized Cooperatives)

Those non-investing members will turn out to be the investing members in this case. In consequence, government subsidies received will change the capital structure of the cooperative and dilute core members' benefit as well which will directly affect on these members' income.

The situations above show the adjustments of the capital structural make more members from the unequal capital contribution FSCs will be involved in the profit distribution process. Correspondingly, the proportion of earning distribution those individual members can get reduced in a certain extent. In addition, taking the differences existed in member's contribution to their cooperatives into account, the law regulated an alternative institutional arrangements. The additional voting rights is a such an example, which will achieve the interest balance among members with different interest orientation and maintain the sustainable improvement of members' common interest under the current "chaxu geju" (Note 6) situation. However, the capital structure changes caused by accepting government subsidies may deprive the additional voting rights from those members who make huge capital contributions to their cooperatives. As a chain reaction, they may change the governance structure and sharply reduce the enthusiasm members with huge capital contribution to participate the governance and management process. For those interests damaged members, they prefer to against the acceptance of government subsidies. On the contrary, non-investing members prefer to use the democratic governance mechanisms to against core members' strategy. In a word, government subsidies may lead interest and behavior conflicts among members in FSCs.

\section{Recommendations}

More emphasis is needed on the improvement of current government incentive institution to enhance the quantity and quality FSCs benefit and raise the usage efficiency of government resources. On the basis of present institutional fundamental, taking the Chapter VII Government Supportive Policies involving in the Law of the PRC on Farmers Specialized Cooperatives as an example, and considering the proper costs, risks, benefit and issues existed in the process FSCs compete for and digest government subsidies, both government and FSCs should develop their strategy-making system with the precondition of two-way choice. 


\subsection{FSCs should selectively choose government subsidies depend on their own}

We believe the win-win situation can be achieved, that is FSCs can both gain government subsidies, and improve their current conditions to adapt the heated competition with the other stakeholders in the market and gain more benefit from their business while they compete for the government incentives, so that can maximize the usage efficiency of the subsidies. In other words, 'win-win' refers to realize the sustainable development of FSCs and the usage efficiency improvement of government subsidies. If the required transaction costs is too high and could not help cooperative to grow, then it is not suitable for this kind of FSCs to compete for government funding. Meanwhile, in accordance with the 'earmark' principle of using government subsidies involved in the law, those acquired funds can be only spent on specific projects. It is difficult for government to target individual FSCs' specific project requirements and provide enough funding to every single FSCs. In this case, some FSCs should reject the temptation of subsidies and make their own growth strategies.

4.2 Government should strengthen the cost-benefit awareness and effectively improve the performance of financial support

The main purpose for supporting FSCs is to strengthen the cooperatives' ability to adapt for the surroundings. Also FSCs can benefit more from the market after having this ability and maximize the usage efficiency of government incentives. Therefore, when the government chooses the potential supportive objects, they should be aware that there are different transaction costs and net income existed among different FSCs. Correspondingly, the practical utility of using subsidies to support the development of cooperatives may be totally different. It is more necessary for government to choose FSCs in their birth and survival periods instead of those successful FSCs. In a word, FSCs which need most support and can improve their marketing competitiveness have the priority to be the objective.

As for some FSCs, the over-support from government is not good for the cultivation of cooperatives' self-development and independency capacity. In reality, those FSCs used taking subsidies as operating target, the money they get from the government always do not been used on the organizational sustainable development and benefit all their members. Instead it secretly turns out to be some members' personal income, which reduces the usage efficiency dramatically. On the other hand, repeating provide support to successful FSCs would also undermine the fairness of competition among FSCs. Therefore, government subsidies should be more used on forming the public service platform for all cooperatives and reduce the current single model of directly financial payment. Moreover, a dynamic, long-term and effective selecting and monitoring mechanism should be established, to prevent those fake cooperatives failing to meet the requirements to squeeze and use the public resources from other deserved cooperatives.

\section{References}

Gang SONG. (2007). Some problems of farmer cooperatives - Review of "farmer cooperatives". Zhejiang Social Sciences, (5), pp. 64.

Hind, A.M. (1994). Cooperatives under performers by nature? An exploratory analysis of cooperative and non-cooperative companies in the agribusiness sector. Journal of Agricultural Economics, (2), pp.213-219.

Jingxin WANG. (2005). The growth of new cooperative organization in rural China. (1st ed.). Beijing: China Economics Publishing House, (Chapter 4).

Peng YUAN. (2001). Research on farmer cooperative organizations in the Chinese rural market development. (1st ed.). Beijing: Social Sciences in China Press, (Chapter 3).

Sarah Franklin and Susan Mckinnon. (2001). Relative values: reconfiguring kinship studies. (1st ed.). Durham: Duke University Press, (Chapter 8).

Wuchang ZHANG. (2000). Economic Organization and Transaction Costs, (1st ed.). Beijing: The commercial press, (Chapter 1).

Xiangzhi KONG and Meidan CHEN. (2009). The new development tendencies of SFCs in China: theoretical studies \& practical exploration. ( $1^{\text {st }}$ ed.). Chendu: Sichuan Science and Technology Press, (Chapter 2).

Xiangzhi KONG and Yanqin GUO. (2006). The farmers' cooperative economic organizations in today's China and the government's function: asurvey in 23 Provinces. Agricultural Economy, (1), pp.54-59.

Xiaoshan ZHANG and Peng YUAN. (1991). Cooperative economy: theory and practical. (1st ed.). Beijing: China City Press, (Chapter 2).

Xiaotong FEI. (2001). Peasant Life in China, (9th ed.). Beijing: The Commercial Press, (Chapter 3).

\section{Notes}

Note 1. According to the Law of the PRC on Farmer Specialized Cooperatives (2006), farmers specialized cooperatives in China are mutual-help economic organizations jointed voluntarily and managed in a democratic manner by the producers and operators of the same kind of farm products or by the providers or users of services 
for the same kind of agricultural production and operation. They mainly serve their members, offering such services as purchasing the means of agricultural production, marketing, processing, transporting and storing farm products, and providing technologies and information related to agricultural production and operation.

Note 2. This principle is quoted form the International Cooperative Alliance (ICA) Statement on the Cooperative Identity. Available: http://www.ica.coop/coop/principles.html.

Note 3. The data above was provided by Beijing Municipal Commission of Rural Affairs.

Note 4. This document confirm that government support to FSCs should cover infrastructure construction, independent grant registration system, quality accreditation of agricultural products, trademarks, marketing net construction, technical training, etc.

Note 5. Aleatory is depending on an uncertain event or contingency as to both profit and loss.

Note 6. The term "chaxu geju" was first coined by the famous Chinese sociologist Xiaotong FEI more than half a century ago. To describe the different structural principles in Chinese society, he wrote 'In Chinese society, the most important relationship-kinship-is similar to the concentric circles formed when a stone is thrown into a lake" (Xiaotong FEI, 2001) In such a network of concentric circles, "everyone stands at the center of the circles produced by his or her own social influence. Everyone's circles are interrelated. One touches different circles at different times and places'. FEI refers to such a mode of social origination as chaxu geju, translated as the "differential mode of association". Through this concept, FEI argues that Chinese society is not group oriented but egocentric. (Sarah Franklin, Susan Mckinnon, 2001)

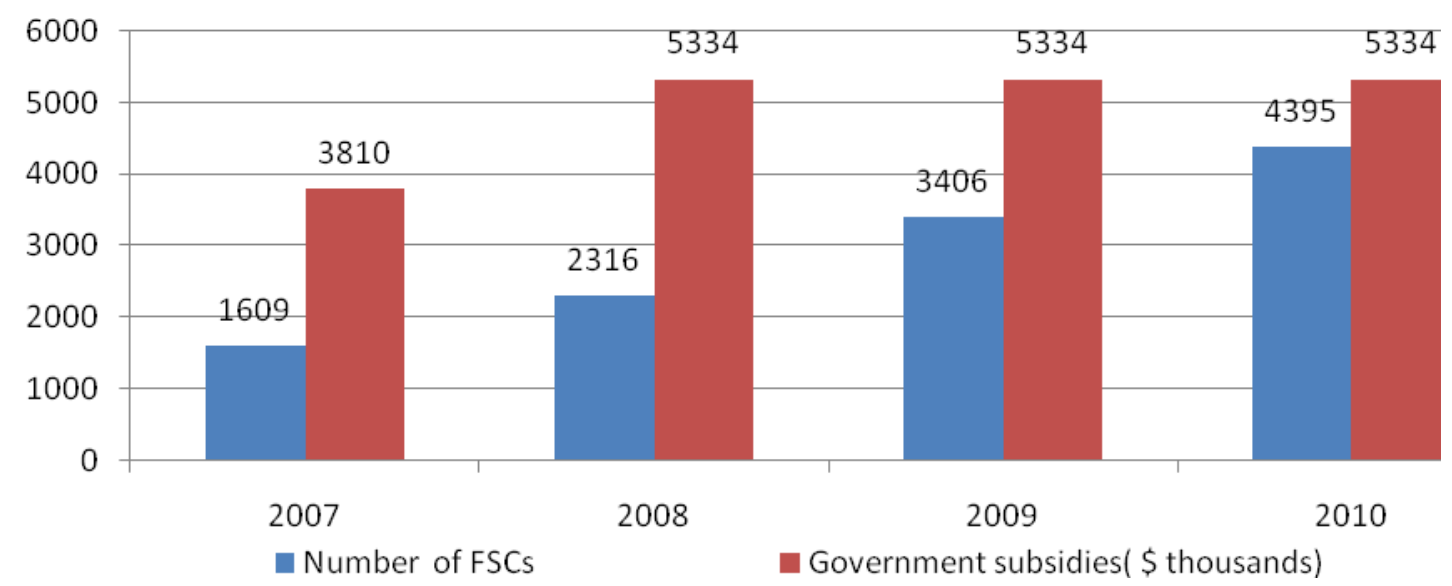

Figure 1. Number of FSCs and government subsidies to FSCs in Beijing Municipal

Source: Beijing Municipal Commission of Rural Affairs, 2010 